\title{
Maxillofacial Radiology 176
}

\author{
SADJ November 2019, Vol. 74 No. 10 p586
}

CJ Nortjé

Below are three very rare and unusual lesions that may present in the jaws. What are the important radiological features and what are your differential diagnoses?
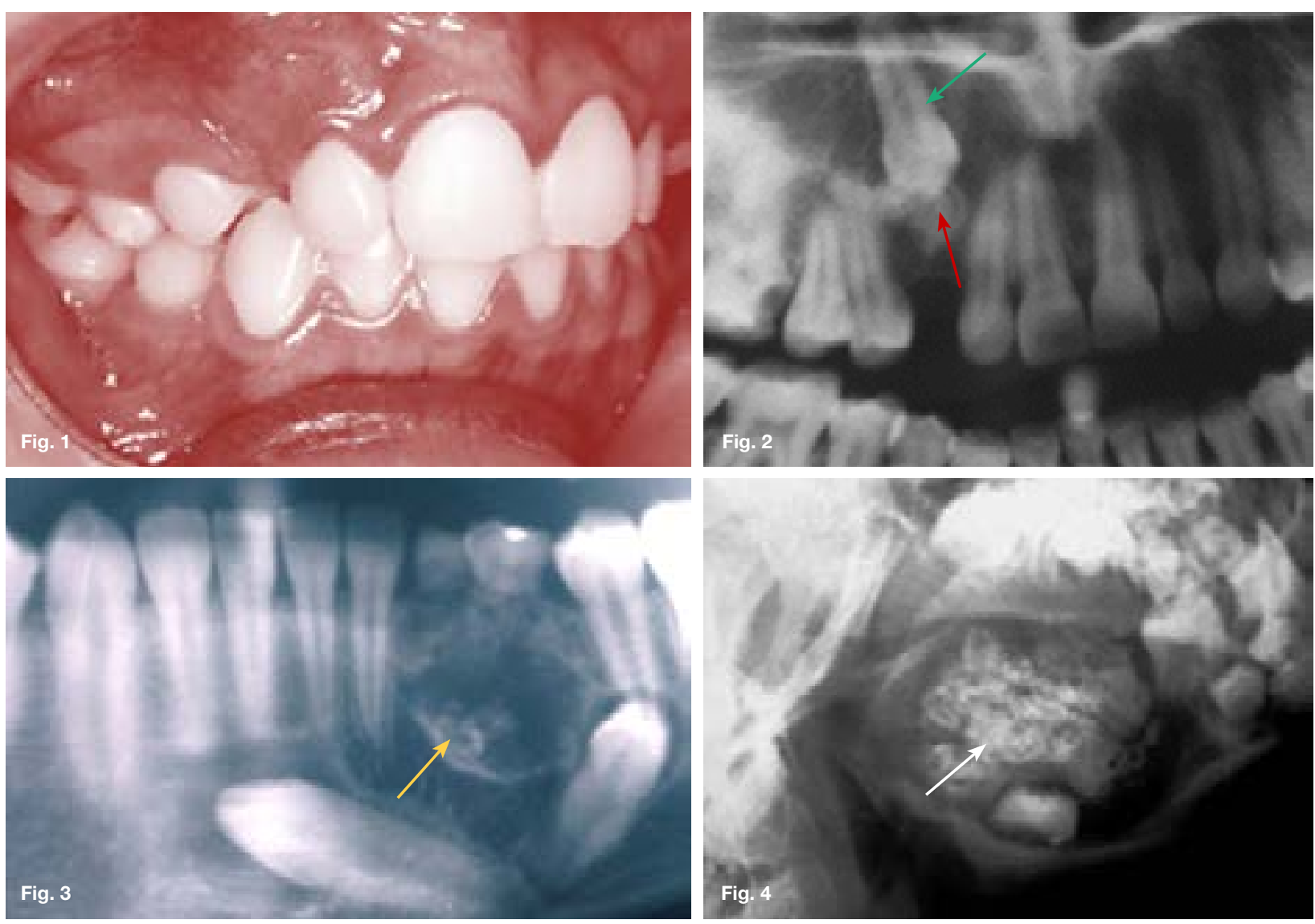

\section{INTERPRETATION}

Figure 1 is of a patient with the complaint that her upper right canine has not erupted. The cropped pantomograph (Figure 2) shows an impacted canine with an irregular low density lesion at the incisal edge, (red arrow) is very similar to the dentin of the impacted canine (green arrow). A diagnosis of a dentinoma was made. This is an extremely rare tumour of odontogenic origin and occurs predominantly in the mandible and is frequently associated with an impacted tooth. The radiographic appearance is not specific, but usually there is a radiolucent area containing a large, solitary opaque mass or smaller masses of calcified material. Figure 3 is a cropped pantomograph of a fourteen year old female presenting with a swelling in the 42-35 region. A mixed radiolucent/radiopacity lesion causing displacement of left mandibular canine and first premolar is discernible. A histological diagnosis of ameloblastic fibro-dentinoma (AFD) was made. The AFD is a rare mixed odontogenic tumour composed of odontogenic epithelium, immature

Christoffel J Nortjé: $B C h D, P h D, A B O M R, D S c$. Faculty of Dentistry, University of the Western Cape.

ORCID Number: 0000-0002-9717-5514

Email: cnortje@uwc.ac.za connective tissue and characterized by the formation of dysplastic dentin (yellow arrow). It is slow growing, is often an asymptomatic lesion with a predilection for males. Radiologically, it shows unilocular or multilocular radiolucency with or without radio-opaque areas. Histologically, it is similar to ameloblastic fibroma but also shows dentin formation. Figure 4 is an oblique lateral radiograph of a five year old male with a slow growing swelling in the premolar/molar region of the left mandible causing expansion and disturbance of eruption of the teeth in the region. Radiographically the lesion is characterized by a well-defined radiolucency containing several small, irregular fragments of tooth material (white arrow). A histological diagnosis of an ameloblastic fibro-odontoma (AFO) was made. The lesion is very similar to the AFD, and consists of soft tissue, odontogenic epithelium, enamel and dentin. Occasionally the tumour is discovered during routine dental radiographic examination.

\section{Reference}

1. Pindborg JJ, Hjorting-Hanson E: Atlas of Diseases of the Jaws, WB Saunders, 1974; 94-6.

2. Farman AG, Nortje CJ, Wood RE: Oral and Maxillofacial Imaging, $1^{\text {st }}$ Ed, Mosby. St. Louis, Missouri 1993; 250-2. 